\title{
CONCEPTUALIZING SPORT EVENT LEGACY
}

\author{
ALANA THOMSON, KATIE SCHLENKER, AND NICO SCHULENKORF
}

UTS Business School, University of Technology, Sydney, Lindfield, NSW, Australia

\begin{abstract}
Events legacies have become a common feature in the public policy rhetoric surrounding sport events of all sizes. Public policy planners and event organizers are increasingly promoting the legacies of sport events to justify significant investments required to host them. Within the context of special events, legacy is most often recognized as the long-term or permanent outcomes for a host city from staging an event. These outcomes include potential economic, tourism, social, physical, and/or environmental factors. However, the justification of legacies from events remains complicated due to inconsistent conceptualizations of legacy across academic and industry practice. While legacy is an increasing component of event bids as well as funding justifications and postevent reports, the concept itself has attracted limited critical analysis. This article puts forth a comprehensive review of literature that has sought to define legacy, from 1991-2008, drawing on event management, sport management, and urban planning contexts. An inductive interpretive analysis of definitions was undertaken, in which key considerations were identified and definitions assessed against these. The analysis revealed five key considerations of legacy in application to the sport event management context. In doing so, this article contributes to both theoretical debate and improved strategic practice surrounding the emergence of "legacy" as justification for staging sport events.
\end{abstract}

Key words: Legacy; Sport events; Strategic management; Event policy

\section{Introduction}

Public policy planners and event organizers are increasingly promoting potential economic, tourism, urban, social, and/or environmental legacies to justify significant public investments required to host special events (Girginov \& Hills, 2008; C. Hall, 2006; Kasimati, 2003; Westerbeek et al., 2005). The event impacts studies that emerged during the 1980s increased our understanding of the potential positive and negative outcomes of events (see Burns, Hatch,
\& Mules, 1986; Ritchie, 1984). However, many impact evaluations of sport events have found that in the short term events have not necessarily provided the positive outcomes that were originally anticipated or promised (Crompton, 1995; Crompton \& McKay, 1994). Subsequently, researchers and policy makers have called for a longer term focus and a more comprehensive evaluation of economic, social, and environmental outcomes.

Over the last 2 decades, the notion of event legacies has emerged as the rationalization behind this 
longer term focus (Bianchi, 2003; Girginov \& Hills, 2008; McIntosh, 2003). Policy statements and popular press coverage regularly discuss event legacies as positive outcomes that a host city can expect by hosting large-scale sport events. One of the earlier articles to consider event legacies outlined that "part of the justification for enormous capital investment in events is the promise of legacy for the host community or nation" (Getz, 1991, p. 30). More recently, Allen, O'Toole, McDonnell, and Harris (2008) highlighted the increased importance of legacy within the event management context, noting that "for some events, particularly large-scale public events, the issue of legacy has become central to the decision to host or create them" (p. 115).

However, the legacy justification is complicated by inconsistent conceptualizations of legacy across academic and industry practice (Gratton \& Preuss, 2008; Matheson, 2010; Moragas, 2003). Available legacy literature outlines the problems involved with defining legacy as "a matter of debate and controversy" (Essex \& Chalkley, 2003, p. 95). To add to the complexity, legacy is regarded as multifaceted (Chalip, 2003), multidimensional (McCloy, 2003; Moragas, 2003), highly politicized (Girginov $\&$ Hills, 2008), and elusive (Cashman, 2003).

The purpose of this review is to identify the key considerations of legacy as defined in the literature for application to sport events. This article provides a review of sport event legacy literature from articles published between 1991 and 2008, focusing on articles which have sought to provide definitions of legacy across fields of event management, sport management, and urban planning contexts. In doing so, the article highlights five key considerations surrounding sport event legacies and outlines management implications for both academics and practitioners.

\section{Research Approach and Literature Review}

A literature search was undertaken to identify a sample of articles that referred to or explored the notion of sport event legacies. For the purposes of this article, only articles that provided a definition of legacy were included. The basis of the sample comprised articles identified as key readings in the field of event management (including Getz, 1991; Moragas, Kennett, \& Puig, 2003; Preuss, 2007).
Building on these, wider reading of related publications identified a further 10 articles that provided definitions of event legacy (Barney, 2003; Chalip, 2003; Chappelet, 2003; Essex \& Chalkley, 2003; Getz, 2005; Hiller, 2000; Kidd, 2003; McCloy, 2003; Preuss, 2003; Roche, 2003). Finally, a Google scholar search was conducted to make sure that additional relevant articles were included; however, only one other article was located (Gratton \& Preuss, 2008) and it was found that articles with legacy definitions were not evident in academic writing post-2008.

The sample contained articles across journals and other academic sources including two tourism and event textbooks, nine papers from the International Symposium on Legacy of the Olympic Games 1984-2000 proceedings, and a further three journal articles published in the Research in Urban Sociology journal, Journal of Sport and Tourism, and International Journal of the History of Sport. These spanned from the early 1990s, with the earliest definition of event legacies occurring in a tourism and event management context (Getz, 1991), through to the most recent article in 2008 (Gratton \& Preuss, 2008). Only articles written in the English language were included.

Based on the review of the collected articles, the lead researcher identified five broad considerations that became apparent across the definitions through an inductive interpretive approach. Author crosschecking was subsequently employed, with the coresearchers checking initial interpretations (Miles \& Huberman, 1994). The five key considerations that emerged from definitions of event legacy were summarized as:

1. Terminology: use of "legacy" as opposed to another term.

2. Legacy as automatically bestowed or needing to be planned.

3. Temporal nature of legacy: permanent or long term.

4. Legacy as positive and/or negative.

5. Legacy as a local and global concept.

Table 1 provides a summary of the definitions featured in the 14 articles and the legacy considerations that emerged through the review. The first column lists the author and year of the article publication. 


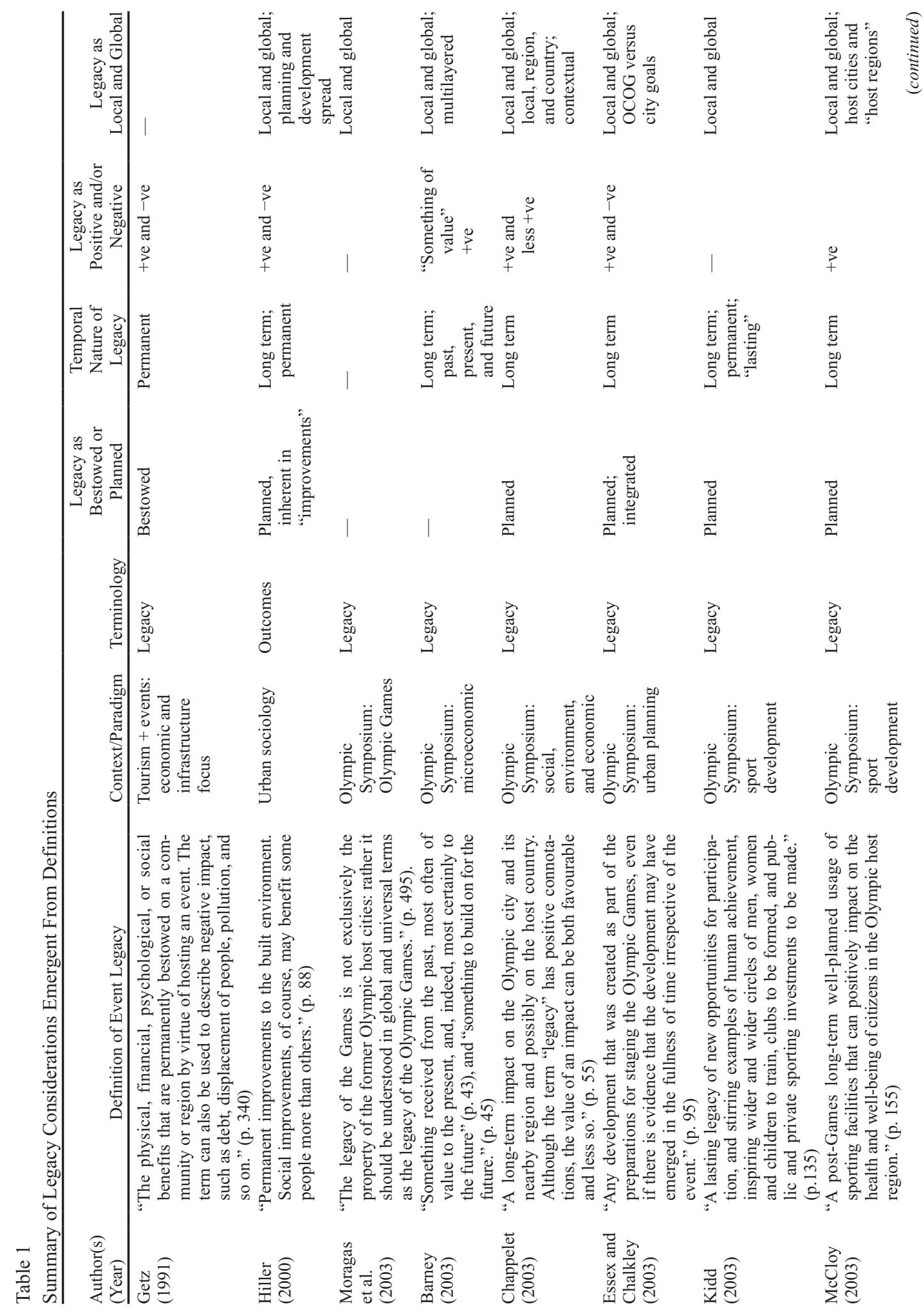




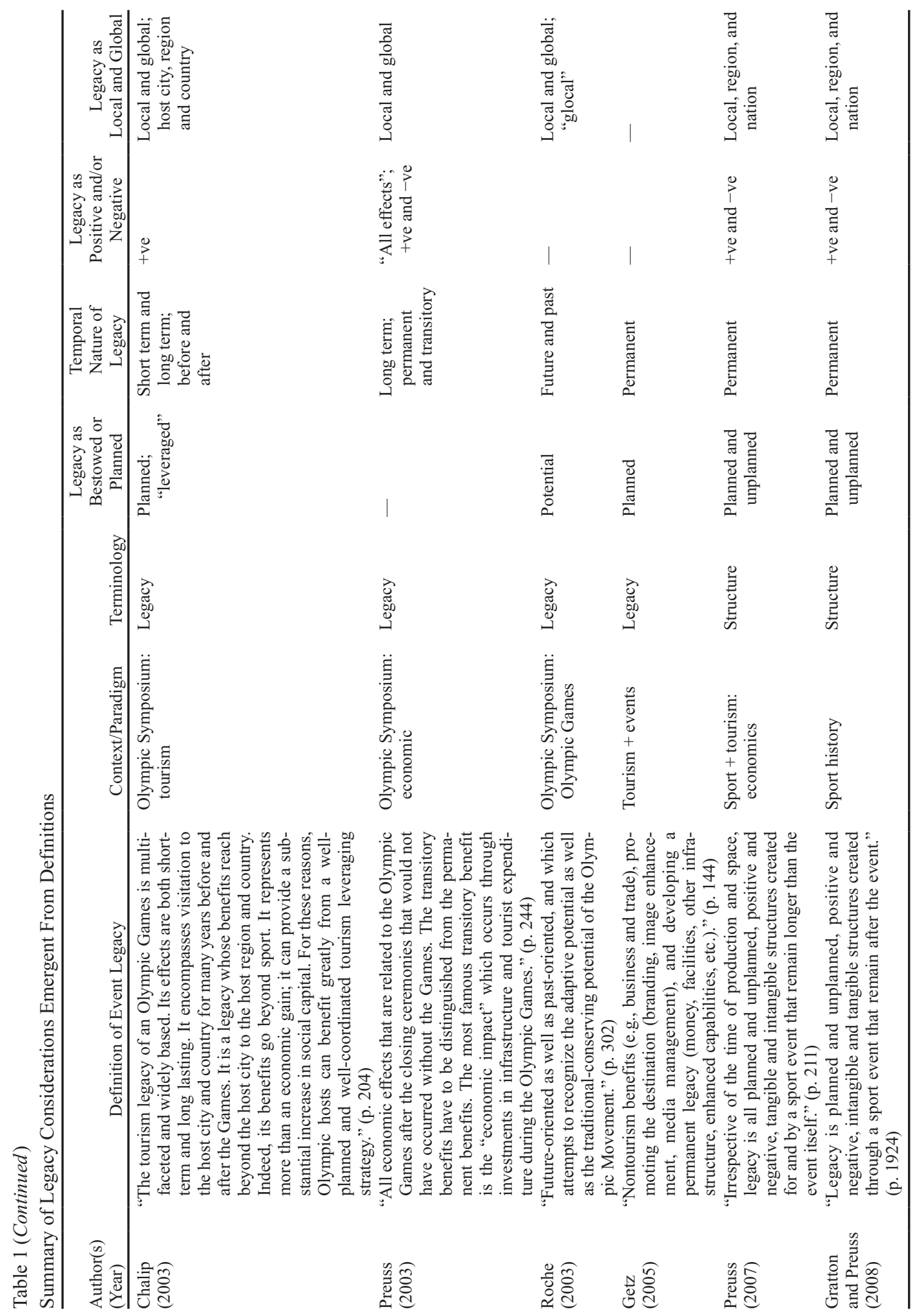


The second column presents the definition included in the article. The third column indicates the context and/or paradigm of the author's approach to defining sport event legacy. The remaining five columns present evidence where applicable of the event legacy considerations identified in the review.

The following review will be presented in order of the considerations identified. Broader theoretical and empirical literature has been drawn upon to highlight and contribute to an understanding of the complexities that exist around the concept of legacy in the sport and event management context. After reviewing each of the considerations, implications for best practice in legacy planning, implementation, and evaluation is provided.

First, the issue of terminology is discussed, focusing on use of the term "legacy" as opposed to other terminology such as "outcome." Second, a discussion is presented addressing the need for strategic legacy planning as opposed to legacies being "bestowed." Third, the temporal dimensions of legacy are explored, considering the "long-term," "sustained," or "permanent" nature of legacies. Fourth, the positive and negative outcomes of legacy are presented. Finally, the local and global dimensions of legacy are explored, with consideration of the different levels at which legacy exists.

\section{Consideration 1: Terminology}

The first consideration that became evident through the thematic review was the issue of terminology when defining and discussing sport event legacies. The definitions highlighted a debate between uses of the term "legacy," as opposed to other terminology such as "impact," "outcome," or "structure." As can be observed in Table 1, the majority of authors use the term "legacy," while Hiller (2000) prefers the term "outcome" and, more recently, Preuss (2007) and Gratton and Preuss (2008) prefer the term "structure" when conceptualizing "legacy."

The problem of using alternate terms is highlighted by Cashman's (2003) criticism of the inadequacy of the term "legacy." He argues that the term legacy is somewhat ambiguous as it has several different meanings in the English language - it can allude to anything that is left over from an event, be that positive or negative in nature. Further, Cashman (2003) explains that there is an absence of a direct translation in European languages and problematic translation to non-European languages. For example, the French translation for legacy is "heritage," and in German it is "inheritance." Both of these terms imply different meanings in the English language context. Preuss (2007) echoes this criticism and outlines that due to the international nature of events, there is an associated need for universally understood terminology for strategic management, policy development, and evaluation. Interestingly, there were no references to the terms "heritage" or "inheritance" in the definitions included in the sample, which may be due to the exclusion of articles not written in the English language.

In line with Cashman's (2003) argument, Preuss (2007) believes that generic definitions are not suited to how the term "legacy" is used in the sport event context. Preuss (2007) highlights three key assumptions of the generic definition of legacy, which suggest that: 1) legacy is something owned; 2) legacy is something passed on by will; and 3) legacy is inherently positive. By addressing each of these three definitional assumptions, Preuss (2007) goes on to offer reasons why they do not translate to a sport event context. First, the assumption that legacies are owned is disputed, given that the legacies from sporting events are often not owned by any particular entity but instead exist as a public good. For example, public amenities, infrastructure, and the psychic capital of the city's residents are nonrival and nonexcludable, meaning everyone has the opportunity to enjoy the legacy. Second, within the sport event context, negative legacies, such as inefficient use of sporting arenas, often exist and were not intended to be left by will. This also supports critique of the third assumption, which sees legacies as inherently positive, when in fact, in the sport event context, there are often negative legacies left behind. While there are valid arguments as to why a term other than legacy could be used, as Cashman (2003) has previously argued, to avoid using the term legacy is problematic considering the wide usage and acceptance that the term now enjoys in both academic and industry arenas.

Best Practice Implications. As has been argued, it is important that common terminology and conceptual understanding of legacy is established 
(Cashman, 2003; Getz, 2002; Preuss, 2007). The search for relevant articles revealed that definitions of legacy in the literature have been limited post2008. Nevertheless, researchers refer to legacy and conduct empirical research investigating legacy, and they appear to assume a common understanding is present. However, as Preuss (2007) has argued, legacy means different things depending on the type of event and the context of the host city. Moving forward, to guarantee a meaningful application of legacy to any size event, host community, and stakeholders, the term legacy - or any other related term adopted by event managers - needs to be defined in all event-related documentation so there is clear direction for organizers and stakeholders to maximize positive legacies from a sport event.

\section{Consideration 2: Legacy as Bestowed or Planned}

The second consideration that became evident through the thematic review was reference to legacies as either bestowed (Getz, 1991) or planned (Chalip, 2003; Essex \& Chalkley, 2003; Preuss, 2007). Those who view legacies as bestowed consider them to be automatic endowments for the city as a result of simply hosting a sport event. This was apparent in the early definition of legacy provided by Getz (1991), which was only mentioned in the glossary of his textbook. Here he defined legacy as "benefits that are permanently bestowed on a community or region by virtue of hosting an event" (p. 340). The assumption of legacies being bestowed may be accurate to a certain extent. For example, due to the scale of mega-events and requirements of host cities to cater for them, there are likely to be infrastructure developments that will inadvertently become legacies for the host city (Carvalhedo, 2003; Castellani, 2003; Westerbeek, Turner, \& Ingerson, 2002).

However, it has been argued that the staging of a sport event does not guarantee that a city or region will automatically experience legacies, in particular, the positive legacies that are sought (Garcia, 2003; Heinemann, 2003; Spilling, 1996). In fact, there are examples of urban infrastructure and sport facilities that have not continued to be used for the public good due to the cost of maintenance (Gold \& Gold, 2007). Further, many cities have been left with significant debts associated with urban infrastructure development and the costs of staging large-scale sport events.

As the legacy justification has become increasingly important over the last 2 decades, there has been much more emphasis on strategic planning for legacy. In particular, attention has been focused on maximizing the positive impacts, reducing the negative impacts, and not leaving anything to chance. The understanding of planning for legacy to achieve desired outcomes has come through in the legacy definitions from 2000 onwards (Chalip, 2003; Essex \& Chalkley, 2003; Getz, 2005; Hiller, 2000; Preuss, 2007).

From the urban development context, Hiller (2000) and Essex and Chalkley (2003) argue the importance of integrating event-related development outcomes into the long-term development goals of the host city and region. They argue that host cities that have experienced successful urban development surrounding Olympic Games are those which have considered the needs of the host city before, during, and after the event and who have embedded event requirements within the long-term urban development needs of the host city (Essex \& Chalkley, 2003; Hiller, 2000). Essex and Chalkley (2003) refer to examples including the Sapporo Winter Olympics of 1972 where less than $5 \%$ of total expenditure was attributed to sport infrastructure; instead, the majority of spending was on transport-related improvements for the region. Similarly, $20 \%$ of the spending surrounding the Grenoble Winter Games was on road systems to decentralize the city and facilitate the growth of new industries (Essex \& Chalkley, 2003).

From the sport development context, McCloy (2003) and Kidd (2003) argue the importance of planning the legacies of both facilities and sport participation. McCloy's (2003) definition emphasizes the need for sport facility developments to meet event requirements, but also to be designed to meet objectives such as enhancing the health and wellbeing of host city and regional communities. Going one step further, Kidd (2003) suggests that the provision of facilities to provide for long-term recreation needs is only one part of the planning required. There is also a need to engage the community within the planning for increased sport participation. Providing new infrastructure and winning medals will not necessarily result in increased participation 
(Veal, Toohey, \& Frawley, 2012); therefore, attention needs to be placed on connecting with local communities through events to inspire sport participation, community involvement in sport clubs, and ongoing investment when the event is over.

From the tourism context, Chalip (2003) argues the importance of planning and implementing event leveraging strategies that will maximize the tourism legacy outcomes locally, regionally, and nationally. He outlines that for benefits of events to extend beyond sporting success, host cities require "a wellplanned and well-coordinated tourism leveraging strategy" (p. 204). This planning should take into account the event life cycle and the objectives of stakeholders from the host city and relevant regions to be able to maximize opportunities in both the short-term and long-term periods before, during, and after an event (Bramwell, 1997; Chalip, 2003, 2004, 2006; Getz, 2005; Spilling, 1996). A more recent definition provided by Getz (2005) also captures this notion of planning through reference to event leveraging strategies. In particular, Getz (2005) highlights opportunities for creating legacies through place marketing and infrastructure development.

In the sport management context, however, the uptake of strategic planning for legacy is a rather new phenomenon. Only recently there has been greater reference to legacy planning around sport events (Matheson, 2010) and the presence of legacy agencies to coordinate schedules of event-themed development initiatives (Girginov \& Hills, 2008). Studies referring to legacy programming include the Manchester Commonwealth Games 2002 (Gratton \& Preuss, 2008; Smith \& Fox, 2007), European Women's Football Championships 2005 (Bell \& Blakey, 2010), the London Olympic Games 2012 (Girginov \& Hills, 2008), and the upcoming Glasgow Commonwealth Games 2014 (Matheson, 2010).

Best Practice Implications. The importance of how legacy occurs, whether bestowed or planned, is highlighted by the extensive coverage in the literature with 9 of the 14 definitions in this study referring explicitly to planning. The majority of authors argue that legacies cannot be left to chance, with an anticipation of bestowal. Moving forward with the application of legacy in a sport event management context, there is an increasing need for legacy planning and subsequent accountability of event planners and policy makers to realize the potential of events in securing long-term social, economic, and environmental outcomes.

\section{Consideration 3: Temporal Nature of Legacy}

The third consideration that became evident through the thematic review was the limited consensus regarding the temporal dimension of legacy. Some authors described the temporal dimension using adjectives such as permanent or lasting (Getz, 1991, 2005; Gratton \& Preuss, 2008; Hiller, 2000; Kidd, 2003; Preuss, 2003, 2007). Others described legacies as existing in the short term or long term, and during and/or after an event (Barney, 2003; Chalip, 2003; Chappelet, 2003; Preuss, 2003).

Descriptions of legacy as being long term, permanent, or lasting have mainly been used in the contexts of tourism infrastructure (Getz, 1991, 2005; Preuss, 2007), urban development (Hiller, 2000; Preuss, 2007), and sport infrastructure (Kidd, 2003). Drawing on the discussion from the previous consideration of "Legacy as Bestowed or Planned," investment in infrastructure also requires comprehensive planning to enable permanent or lasting legacies, and to avoid infrastructure being underutilized and labeled as "white elephants." Here, an increasingly common trend is the use of temporary infrastructure as a significant contributor to venue management practices for staging sport events (Taylor \& Edmondson, 2007). This was recently observed in the Beijing Olympics (L. Hall \& Callick, 2008), the Melbourne FINA World Swimming Championships 2007 (Sport and Recreation Victoria, 2007), and is also planned for the Glasgow Commonwealth Games 2014 (Matheson, 2010) and the 2022 FIFA World Cup in Qatar. Thus, the notion of permanent legacies will not necessarily apply to all types of legacies that are potentially gained by hosting sport events.

Descriptions of legacy as short term or long term provide an alternate perspective to permanent and lasting, recognizing that various types of benefits may impact a host city and its region for varied lengths of time. For example, Preuss (2003) outlines that economic benefits from tourist spending and event-related investments tend to be more transitory in nature compared to infrastructure developments. 
Chappelet (2003) refers to legacy as being long term by definition, and discusses the importance of event size and the context of the host city in determining whether a legacy will be experienced for the short term or long term. For example, a comparison of two cities may reveal that one city has a large inventory of hotel rooms for event tourists while the other one does not have adequate capacities. While both cities would experience the shortterm economic benefit from the tourism influx, the city without the inventory of hotel rooms has the potential for greater long-term tourism legacies due to the investment in hotel infrastructure that would need to be put in place to host a large-scale sport event.

The idea of short term and long term also links with the idea of legacy being located before, during, and after the event. For example, both Roche (2003) and Barney (2003) discuss the reputation and prestige of the Olympic Games and the implications this has for the cumulative goodwill and commercial potential of such an event. These notions of goodwill and commercial potential are evident throughout the entire event life cycle. Barney (2003) discusses the symbolic capital of the Olympic rings, outlining that the commercial value of the rings is manifest through ongoing activity. He argues that each host city for the Games receives symbolic value from the previous event, and then passes its own symbolic value onto the next event. This illustrates that the legacy of symbolic value, goodwill, and commercial potential of the Olympic Games is not limited to a specific point in time, but something that its owner, the IOC, needs to continually manage before, during, and after the event.

Best Practice Implications. The importance of the temporal nature of legacy was highlighted by the extensive coverage in the literature. This consideration has highlighted both the complexities of long-term, lasting, and permanent legacies, and the nature of legacies existing before, during, and after an event. Importantly, sport event legacies do not only exist after the event. Moving forward, consideration of temporal dimensions is critical in setting boundaries for planning and implementation of legacy and for establishing time lines for event evaluation. Further, large-scale sport events should be conceptualized as having opportunities for legacy at each stage of the event life cycle to maximize positive legacies while limiting the negatives.

\section{Consideration 4: Legacy as Positive and/or Negative}

The fourth consideration that became evident through the thematic review was the positive and negative potential of legacies. This consideration is understood through the varied legacies that a city or region and its population may experience. Although host cities bid for large-scale sport events based on the potential benefits to the city, there has been an acknowledgement from the earliest literature that outcomes may not always be positive, and there are many examples of negative legacies from hosting sport events (Getz, 1991).

Chappelet's (2003) definition offers an important insight, stating "although the term 'legacy' has positive connotations, the value of an impact can be both favorable and less so" (p. 55). Planning to maximize positive outcomes and limit negative outcomes is complicated by the fact that legacies may be subject to perception, and that two stakeholders may take very different viewpoints on the same legacy outcome. As an example, from one perspective, policy makers and business elites may perceive a rejuvenated public space and business precinct as a positive legacy. Yet, from another perspective, there may be lower socioeconomic groups who become displaced from their homes and communities as a result of rezoning legislation, increased land values, and rental prices (Garcia, 2003; Searle, 2003), and therefore view this same legacy as negative.

Interestingly, only half of the definitions included in Table 1 considered that legacies can be both positive and negative (Chappelet, 2003; Essex \& Chalkley, 2003; Getz, 1991; Gratton \& Preuss, 2008; Hiller, 2000; Preuss, 2003, 2007). Hiller (2000) outlined negatives through associated costs instilled by urban development, such as displacement of people living in localities earmarked for gentrification. Chappelet (2003) highlighted the impact that infrastructure development for the Winter Olympics can have on alpine environments, while Searle (2002) mentioned the ongoing costs to tax payers for infrastructural development. These studies have argued the critical need to take a comprehensive 
planning approach for sport events to maximize positive legacies, and just as importantly, minimize the negative legacies.

Best Practice Implications. The limited and somewhat vague coverage of the positive and negative nature of legacies demonstrates a lack of rigorous critique of the duality of the concept and provides insufficient guidance for how such outcomes may be dealt with. It is important to acknowledge this consideration of legacy, as inadequate planning may result in a host city or region experiencing the negative legacies from an event for a long time, including financial implications, environmental impacts, and social impacts. Moving forward, both positive and negative legacies need to be considered, assessed, and managed across all stakeholders contributing to, or affected by, an event in order to maximize positive, and limit negative legacy outcomes.

\section{Consideration 5: Legacy as Local and Global}

The fifth consideration that became evident through the thematic review was the local and global nature of legacy. The literature revealed a contextual and dynamic nature of sport events, reflecting a relationship between local and global interests. The definitions reviewed indicated that a range of legacies can potentially be achieved for the host city, region, country, and event owners through the hosting of a sport event (Gratton \& Preuss, 2008; Moragas et al., 2003; Preuss, 2007).

Roche (2003) explains that sport events are increasingly awarded to a host city, rather than host countries. As part of this, sport events have played an important role in establishing the status of cities as "world cities." Furthermore, this change affects how the sport event is considered and perceived at various levels of impact, from local communities, to host cities, to the nation, and beyond. Roche (2003) uses the term "glocal" to describe the nature of contemporary sport events, where they operate on various levels, within a local community as well as in the global community. There is consistently significant expectation that a city-based event can be leveraged so that the city, region, and nation can experience long-term benefits, including those related to physical activity and sport (Department for Culture Media and Sport, 2008; McCloy, 2003; Weed et al., 2009), tourism (Chalip, 2003; Chappelet, 2003; Gardiner \& Chalip, 2006), and urban development (Smith, 2010).

In addition to identifying the continuum of legacies achievable for the host city, region, and country, the literature also suggests that legacies can be conceptualized differently depending on the stakeholders, whether it is the host city or the organizations that govern the rights to a particular sport event (Gratton \& Preuss, 2008; Matheson, 2010; Preuss, 2007). Each stakeholder has different purposes and interests in staging the event and different expectations as to what will constitute their legacy. Thus, there is a need for community engagement and collaboration throughout the planning processes to ensure legacies are realized for all stakeholders involved (Matheson, 2010; Misener \& Mason, 2006).

Best Practice Implications. This consideration highlighted that the spectacle of a sport event can reach beyond just the host community; however, each event will be different in terms of its size and reach. The review outlines the importance of balancing the needs of the event, host city, and other stakeholders. For any scale event, from global spectacles of the Olympic Games and FIFA World Cups to locally based sport events, there is a need to consider all stakeholders involved. Moving forward, events should be conceptualized in their broadest possible context to encourage stakeholder support and provide opportunities for legacies to be realized for the host city, as well as the wider region, nation, and beyond.

\section{Summary and Outlook}

There has been an increase in the use of legacy as a justification for government involvement in sport events; however, there exists a limited consensus around the conceptualization of legacy in the academic literature. Considering that the area of event legacy is a context where the academic field is leading practice in many cases, this limited consensus makes it difficult for event organizers, policy makers, and event stakeholders to work towards achieving meaningful legacy outcomes. 
This article sought to provide a deeper understanding of how legacy is conceptualized in the academic literature. Fourteen definitions of legacy were reviewed and five key considerations were identified. Stemming out of this review are several implications for best practice for legacy planning:

- Legacy, or any other related term that is applied within an event setting, needs to be defined from the earliest stages of the event so that event managers, policy makers, and stakeholders have a clear vision for what is to be achieved.

- Planning for legacy must take place at the conception of the event, rather than being considered as an afterthought; this means that legacy should be defined, responsibilities assigned, stakeholders identified, and strategies planned from the outset of the event.

- By positioning legacy planning at the conception of the event, there is a potential for outcomes to be realized at various stages of the event life cycle, rather than only at the conclusion of the event.

- Legacy planners must acknowledge that depending on various view points, legacies may have positive and/or negative consequences; attempts should be made to maximize positive legacies and limit the negative ones.

- Events of all sizes should be conceptualized in their broadest possible context to ensure that positive legacies can be realized for the host city, as well as the wider region, nation, and beyond; engaging stakeholders early on is a way to ensure that the event legacies can have maximum reach.

There is a definite need for further empirical research and conceptual development in the area of legacy management for special events, and sport events specifically. For legacy to continue as a major policy justification, the application of legacy in the sport event management context must be further investigated. The authors will look to build on the identification of legacy considerations by empirically testing these five considerations on a number of sport event case studies from around the world. Future research will analyze how legacy is conceptualized, planned, and evaluated from different policy and strategic management perspectives.

\section{Acknowledgements}

The authors would like to thank reviewers of an earlier version of this article presented at the International Event Management Research Symposium, July 6-8, 2009, Gold Coast, Australia, and the reviewers of Event Management, for their comments that helped strengthen this article.

\section{References}

Allen, J., O’Toole, W., McDonnell, I., \& Harris, R. (2008). Festival and special event management (4th ed.). New York: Wiley.

Barney, R. K. (2003). The Olympic legacy of wealth: A double edged sword. Paper presented at the Legacy of the Olympic Games 1984-2000, International Symposium.

Bell, B., \& Blakey, P. (2010). Do boys and girls go out to play? Women's football and social marketing at Euro 2005. International Journal of Sport Management and Marketing, 7(3/4), 156-172.

Bianchi, C. (2003). The role of archives and documents in the legacy of the Olympic movement. Paper presented at the Legacy of the Olympic Games 1984-2000, International Symposium.

Bramwell, B. (1997). Strategic planning before and after a mega-event. Tourism Management, 18, 167-176.

Burns, J. P. A., Hatch, J. H., \& Mules, T. J. (1986). The Adelaide Grand Prix: The impact of a special event. Adelaide: The Centre for South Australian Economic Studies.

Carvalhedo, A. (2003). Tourism as a cultural legacy of the modern Olympic Games. Paper presented at the Legacy of the Olympic Games 1984-2000, International Symposium.

Cashman, R. (2003). What is “Olympic legacy?" Paper presented at the Legacy of the Olympic Games 1984-2000, International Symposium.

Castellani, V. (2003). Torino 2006: Planning and organising Olympic legacy. Paper presented at the Legacy of the Olympic Games 1984-2000, International Symposium.

Chalip, L. (2003). Tourism and the Olympic Games. Paper presented at the Legacy of the Olympic Games 19842000, International Symposium.

Chalip, L. (2004). Beyond impact: A general model for sport event leverage. In B. Ritchie \& D. Adair (Eds.), Sport tourism: Interrelationships, impacts and issues (pp. 226252). Clevedon, UK: Channel View Publications.

Chalip, L. (2006). Towards social leverage of sport. Journal of Sport \& Tourism, 11(2), 109-127.

Chappelet, J. L. (2003). The legacy of the Olympic Winter Games: An overview. Paper presented at the Legacy of the Olympic Games 1984-2000, International Symposium.

Crompton, J. (1995). Economic impact analysis of sports facilities and events: Eleven sources of misapplication Journal of Sport Management, 9(1), 14-35. 
Crompton, J., \& McKay, S. (1994). Measuring the economic impacts of festivals and events: Some myths, applications and ethical dilemmas. Festival Management \& Event Tourism, 2(1), 33-43.

Department for Culture Media and Sport. (2008). Before, during and after: Making the most of the London 2012 Games. London: Author.

Essex, S., \& Chalkley, B. (2003). The infrastructural legacy of the Summer and Winter Olympic Games: A comparative analysis. Paper presented at the Legacy of the Olympic Games 1984-2000, International Symposium.

Garcia, B. (2003). Securing sustainable legacies through cultural programming in sporting events. Paper presented at the Legacy of the Olympic Games 1984-2000, International Symposium.

Gardiner, S., \& Chalip, L. (2006). Leveraging a mega-event when not the host city: Lessons from pre-Olympic training. Gold Coast, Australia: Sustainable Tourism CRC.

Getz, D. (1991). Festivals, special events, and tourism. New York: Van Nostrand Reinhold.

Getz, D. (2002). Event studies and event management: On becoming an academic discipline. Journal of Hospitality and Tourism Management, 9(1), 12-23.

Getz, D. (2005). Event management \& event tourism (2nd ed.). Elmsford, NY: Cognizant Communication Corporation.

Girginov, V., \& Hills, L. (2008). A sustainable sports legacy: Creating a link between the London Olympics and sports participation. International Journal of the History of Sport, 25(14), 2091-2116.

Gold, J. R., \& Gold, M. M. (2007). Olympic cities: City agendas, planning, and the world's games, 1896-2012. New York: Routledge.

Gratton, C., \& Preuss, H. (2008). Maximizing Olympic impacts by building up legacies. The International Journal of the History of Sport, 25(14), 1922-1938.

Hall, C. (2006). Urban entrepreneurship, corporate interests and sports mega-events: The thin policies of competitiveness within the hard outcomes of neoliberalism. Sociological Review, 54(2), 59-70.

Hall, L., \& Callick, R. (2008, August 26). Olympic sites to become part of Beijing routine. The Australian.

Heinemann, K. (2003). The Olympic Games: Short-term economic impacts or long-term legacy? Paper presented at the Legacy of the Olympic Games 1984-2000, International Symposium.

Hiller, H. (2000). Toward an urban sociology of megaevents. Research in Urban Sociology, 5, 181-205.

Kasimati, E. (2003). Economic aspects of the Summer Olympics: A review of related research. The International Journal of Tourism Research, 5(6), 433-444.

Kidd, B. (2003). The global sporting legacy of the Olympic movement. Paper presented at the Legacy of the Olympic Games 1984-2000, International Symposium.

Matheson, C. (2010). Legacy planning, regeneration and events: The Glasgow 2014 Commonwealth Games. Local Economy, 25(1), 10-23.
McCloy, C. (2003). Facilities "sport for all" and the Toronto 2008 Olympic bid. Paper presented at the Legacy of the Olympic Games 1984-2000, International Symposium.

McIntosh, M. J. (2003). The Olympic bid process as the starting point of the legacy development. Paper presented at the Legacy of the Olympic Games 1984-2000, International Symposium.

Miles, M., \& Huberman, A. (1994). Qualitative data analysis: An expanded sourcebook. Thousand Oaks, CA: Sage Publications.

Misener, L., \& Mason, D. (2006). Creating community networks: Can sporting events offer meaningful sources of social capital? Managing Leisure, 11, 39-56.

Moragas, M. (2003). Foreward. Paper presented at the Legacy of the Olympic Games 1984-2000, International Symposium.

Moragas, M., Kennett, C., \& Puig, N. (2003, 2002). Conclusions and recommendations. Paper presented at the Legacy of the Olympic Games 1984-2000, International Symposium, Lausanne.

Preuss, H. (2003). Rarely considered economic legacies of Olympic Games. Paper presented at the Legacy of the Olympic Games 1984-2000, International Symposium.

Preuss, H. (2007). The conceptualisation and measurement of mega sport tourism. Journal of Sport \& Tourism, 12(3-4), 207-227.

Ritchie, J. R. B. (1984). Assessing the impact of hallmark events: Conceptual and research issues. Journal of Travel Research, 23(1), 2-11.

Roche, M. (2003). The Olympics and the development of "global society." Paper presented at the Legacy of the Olympic Games 1984-2000, International Symposium.

Searle, G. (2002). Uncertain legacy: Sydney's Olympic stadiums. European Planning Studies, 10(7), 845-860.

Searle, G. (2003). The urban legacy of the Sydney Olympic Games. Paper presented at the Legacy of the Olympic Games 1984-2000, International Symposium.

Smith, A. (2010). Leveraging benefits from major events: Maximising opportunities for peripheral urban areas. Managing Leisure, 15(3), 161-180.

Smith, A., \& Fox, T. (2007). From "event-led" to "eventthemed" regeneration: The 2002 Commonwealth Games legacy programme. Urban Studies, 44(5/6), 1125-1143.

Spilling, O. (1996). Mega-event as strategy for regional development: The case of the 1994 Lillehammer Winter Olympics. Entrepreneurship \& Regional Development, 8(4), 321-343.

Sport and Recreation Victoria. (2007). 12th FINA World Championships summary report. Melbourne, Australia: Author.

Taylor, M., \& Edmondson, I. (2007). Major sporting eventsplanning for legacy. Municipal Engineer, 160(ME4), 171-176.

Veal, A., Toohey, K., \& Frawley, S. (2012). The sport participation legacy of the Sydney 2000 Olympic Games and other international sporting events hosted in Australia. 
Journal of Policy Research in Tourism, Leisure and Events, 4(2), 155-184.

Weed, M., Coren, E., Fiore, J., Mansfield, L., Wellard, I., Chatziefstathiou, D., et al. (2009). A systematic review of the evidence base for developing a physical activity and health legacy from the London 2012 Olympic and Paralympic Games. London: SPEAR.
Westerbeek, H., Smith, A., Turner, P., Emery, P., Green, C., \& Leeuwen, L. V. (2005). Managing sport facilities and major events. Crows Nest, Australia: Allen \& Unwin.

Westerbeek, H., Turner, P., \& Ingerson, L. (2002). Key success factors in bidding for hallmark sporting events. International Marketing Review, 19(2/3), 303-322. 


\section{Event Management}

Title Details

\begin{tabular}{|l|}
\hline \multicolumn{1}{|l|}{ Related Titles } \\
\begin{tabular}{|l|} 
Alternative Media \\
Edition (1)
\end{tabular} \\
\hline Lists \\
\hline Marked Titles (0) \\
\hline Search History \\
\hline event management - \\
\hline (9343) \\
\hline
\end{tabular}

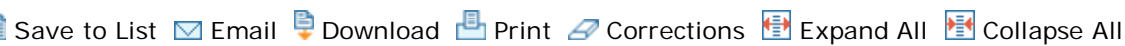

\begin{tabular}{|c|c|}
\hline \multicolumn{2}{|l|}{ Basic Description } \\
\hline ritle & Event Management \\
\hline SSN & $1943-4308$ \\
\hline Publisher & Cognizant Communication Corporation \\
\hline Country & United States \\
\hline Status & Active \\
\hline Frequency & Quarterly \\
\hline -anguage of Text & Text in: English \\
\hline Refereed M & Yes \\
\hline Abstracted / I ndexed & Yes \\
\hline Serial Type & Journal \\
\hline Content Type & Academic / Scholarly \\
\hline Format & Online \\
\hline Website & https://www.cognizantcommunication.com/journal-titles/event-management \\
\hline Description & $\begin{array}{l}\text { Publishes articles intended to meet the needs of an evolving profession. Deal } \\
\text { with the business of special events for non-profit and public organizations to } \\
\text { carry out the missions and as a catalyst for community development. }\end{array}$ \\
\hline \multicolumn{2}{|c|}{ Subject Classifications } \\
\hline \multicolumn{2}{|c|}{ Additional Title Details } \\
\hline \multicolumn{2}{|c|}{ Title History Details } \\
\hline \multicolumn{2}{|c|}{ Publisher \& Ordering Details } \\
\hline \multicolumn{2}{|c|}{ Price Data } \\
\hline \multicolumn{2}{|c|}{ Online Availability } \\
\hline \multicolumn{2}{|c|}{ Abstracting \& Indexing } \\
\hline \multicolumn{2}{|c|}{ Other Availability } \\
\hline Demographics & \\
\hline
\end{tabular}

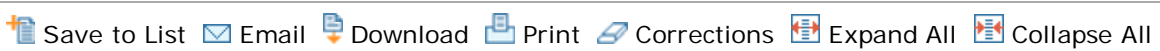

